\title{
Looking for the best anti-colitis medicine: A comparative analysis of current and prospective compounds
}

\author{
Anastasiya A. Chumanevich ${ }^{1}$, Anusha Chaparala ${ }^{1}$, Erin E. Witalison ${ }^{1}$, Hossam \\ Tashkandi ${ }^{1}$, Anne B. Hofseth ${ }^{1}$, Corey Lane ${ }^{1}$, Edsel Pena ${ }^{2}$, Piaomu Liu ${ }^{2}$, Doug L. \\ Pittman ${ }^{1}$, Prakash Nagarkatti ${ }^{3}$, Mitzi Nagarkatti ${ }^{3}$, Lorne J. Hofseth ${ }^{1}$ and Alexander \\ A. Chumanevich ${ }^{1}$ \\ ${ }^{1}$ Department of Drug Discovery and Biomedical Sciences, South Carolina College of Pharmacy, University of South Carolina, \\ SC, USA \\ 2 Department of Statistics, University of South Carolina, Columbia, SC, USA \\ ${ }^{3}$ School of Medicine, University of South Carolina, Columbia, SC, USA \\ Correspondence to: Alexander A. Chumanevich, email: chumanev@mailbox.sc.edu \\ Keywords: colitis, colon, inflammation, dextran sulfate sodium, CAM, FDA
}

Received: November 11,2016 Accepted: November 15,2016 Published: December 10, 2016

\section{ABSTRACT}

Ulcerative colitis (UC) is a chronic lifelong inflammatory disorder of the colon, which, while untreated, has a relapsing and remitting course with increasing risk of progression toward colorectal cancer. Current medical treatment strategies of UC mostly focus on inhibition of the signs and symptoms of UC to induce remission and prevent relapse of disease activity, minimizing the impact on quality of life, but not affecting the cause of disease. To date, however, there is no single reliable treatment agent and/or strategy capable of effectively controlling colitis progression throughout the patient's life without side effects, remission, or resistance. Taking into consideration an urgent need for the new colitis treatment strategies, targets and/ or modulators of inflammation, we have tested current and prospective compounds for colitis treatment and directly compared their anti-colitis potency using a dextran sulfate sodium (DSS) mouse model of colitis. We have introduced a composite score - a multi-parameters comparison tool - to assess biological potency of different compounds.

\section{INTRODUCTION}

Correlated with inflammatory bowel disease (IBD), ulcerative colitis and Crohn's disease are characterized as two prevailing chronic illnesses with obscure causing agents, conditions, and perennial damage. Autoimmune gastrointestinal disorders heighten colon cancer risk with progressing severity through longer duration of colitis, greater anatomic colitis extent, and other/additional potentially contributing carcinogenic inflammatory pathways [1]. In ulcerative colitis patients, the risk of occurrence of colitis-associated colorectal cancer increases with age $[2,3]$.

Due to advances in the understanding of IBD in the past two decades, several FDA-approved drugs are currently available for colitis treatment.

For the mild form of colitis, 5-Aminosalicylic acid (5-ASA) and its derivatives (e.g. sulfasalazine and mesalamine) have been the standard treatment, and may play a chemopreventive role against colitis-driven colon cancer [4]. However, the response rates to these drugs usually are in the range of $40-60 \%$, and are never $100 \%$ [5]. Moreover, there are serious side-effects associated with 5-ASA treatment of colitis, including hepatitis, pancreatitis, and pulmonary dysfunction [6], and in some cases, these agents can even increase the colitis severity [5].

For moderate-to-severe forms of colitis, immunosuppressive agents (mainly against $\mathrm{TNF} \alpha$ ) are widely used, and have become the standard of care. However, this aggressive strategy has extremely dangerous side effects, including a risk for non-Hodgkins lymphoma [7], and an increased risk of infection, especially tuberculosis and reactivation of viral hepatitis [8-10]. Other immune modulators used in the clinic include Azathioprine and mercaptopurine, but these work 
extremely slowly (i.e. up to three months before clinical effects take place), and also include side effects, such as allergic reactions, infections, hepatic and pancreatic inflammation, and cancer $[9,11]$.

Another anti-colitis agent, Cyclosporine A, which is normally reserved for patients who do not adequately respond to other medications, begins working in one to two weeks, but with severe side effects, including kidney damage and fatal infections $[9,12]$.

Corticosteroids can help reduce inflammation, but also possess side effects such as weight gain, facial hair in men and women, high blood pressure, type 2 diabetes, osteoporosis, and susceptibility to infections [9].

Thus, there is no current reliable treatment strategy for colitis and the prevention of colon cancer associated with colitis (especially moderate to severe) that lacks side effects, completely inhibits the signs and symptoms of disease pathology, and overcomes patients' eventual resistance to many treatment agents. For these reasons, new treatment strategies, targets, and/or new modulators of inflammation with none or minimal toxicity are necessary to battle colitis and prevent colon cancer.

Our lab has a long history of studying natural complementary and alternative medicine (CAM) compounds, as well as synthetic small molecule compounds to battle colitis and colon cancer associated with colitis. We have shown that the crude extract from the plant American Ginseng (AG), and a product of its further fractionation - a Hexane fraction of AG (HAG) effectively suppresses colitis and colon cancer through apoptosis of inflammatory cells and cell cycle arrest of colon cancer cells, involving preferential suppression of STAT/iNOS signaling in activated macrophages [13], prevention of DNA damage in colon cells [14], and prevention of colon cancer cell migration through enhanced miR-29b expression [15]. Similarly, resveratrol, another naturally occurring compound, is an effective suppressor of tumor-promoting inflammation [16-18], most likely by enhancing the expression of silent mating type information regulation (SIRT-1) and subsequent downregulation of $\mathrm{NF}-\kappa \mathrm{B}$, which plays a crucial role in colitis and colon cancer associated with colitis [19].

Recently we have identified and described several synthetic small molecule agents that effectively battle colitis in mice. Among these - Cl-Amidine [20, 21] and its derivative BB-Cl-Amidine [22, 23]. Both of these compounds inhibit the protein arginine deiminase (PAD) family of enzymes. Dysregulated activity of these enzymes plays a substantial role in the onset and progression of multiple human chronic conditions, including colitis and colon cancer [24-28]. In our previous studies, we have shown that these PAD inhibitors effectively suppress ulcerative colitis in the dextran sulfate sodium (DSS) mouse model, and can be effectively used to prevent and treat this high colon cancer risk disease [29-32].
Our latest advance in the treatment of IBD involves the use of the FDA-approved anti-malarial drug, quinacrine. Quinacrine has a long history of successful applications for the treatment of malaria, tape-worm infections, giardiasis and systemic lupus erythematosus, possesses antioxidant properties, and has efficacy against autoimmune disorders, such as rheumatoid arthritis with rare, but mild side effects [33-39]. We have shown that quinacrine successfully suppresses colitis without any indication of toxicity or side effects in two mouse models of UC [40].

In this study, we have tested six compounds, including CAMs and synthetic drugs known to possess anti-colitis properties, to directly compare their anti-colitis potency versus two current FDA-approved treatments, in three doses each, using a DSS mouse model of colitis.

\section{RESULTS}

\section{Suppression of colitis in a DSS mouse model of colitis in a dose-dependent manner}

$\mathrm{UC}$ is associated with chronic inflammation in the bowels. We tested all compounds on mice to directly compare their efficiency to suppress DSS-induced acute colitis based on histological inflammation scoring. The histological inflammation score was determined from the H\&E-stained colon sections of each mouse treated with test compounds during 17 days of exposure to DSS, taking into consideration the inflammation severity and extent, ulceration areas, as well as pathological crypt changes. Supplemental Figure 1 contains representative images, demonstrating our approach. The comparative results are shown in Figure 1 and in Table 1.

As expected, all tested agents have successfully suppressed the progression of colitis in a dose-dependent manner, ranging in the following order from the most to the least effective: Resveratrol $>$ Quinacrine $>H A G$ $>\mathrm{BB}$-Cl-Amidine $>\mathrm{AG}>\mathrm{Cl}$-Amidine $>$ Olsalazine + Cyclosporine A combination $>5-A S A$. In general, the highest tested doses of each compound were most effective against colitis, reducing moderate to severe inflammation and mild ulceration in the DSS only treated group with a histological score of $25.9 \pm 1.6$ to mostly mild inflammation and ulceration in the drug-treated groups with histological scores in the range of $7.2 \pm 1.2$ for the Resveratrol group at $75 \mathrm{mg} / \mathrm{kg}$ group to $19.4 \pm 2.5$ for the 5 -ASA group at $25 \mathrm{mg} / \mathrm{kg}$ group. Overall, all tested CAM and small molecule compounds were up to two fold more efficient in inhibiting the severity and extent of colitis in comparison to the clinically used FDA-approved agents 5-ASA and Olsalazine / Cyclosporine A combinations.

Since mouse colon length decreases with 
Table 1: Gross characteristics of treated groups

\begin{tabular}{|c|c|c|c|c|c|c|c|c|}
\hline Treatment Groups & $\begin{array}{l}\text { Starting } \\
\text { Weight, g }\end{array}$ & $\begin{array}{c}\text { Ending } \\
\text { Weight, } g\end{array}$ & $\begin{array}{c}\text { Weight } \\
\text { Difference, } \mathrm{g}\end{array}$ & $\begin{array}{c}\text { Colon } \\
\text { Length, } \mathrm{cm}\end{array}$ & $\begin{array}{l}\text { Inflammation } \\
\text { Score }\end{array}$ & $\begin{array}{c}\text { RBC, } \\
\mathrm{b} / \mathrm{mm}^{3}++\end{array}$ & $\begin{array}{l}\text { WBC, } \\
\mathrm{m} / \mathrm{mm}^{3}+\end{array}$ & $\begin{array}{l}\text { Lymphocytes, } \\
\mathrm{m} / \mathrm{mm}^{3}+\end{array}$ \\
\hline Water & $24.4 \pm 0 . .46$ & $26.2 \pm 0.60$ & $1.8 \pm 0.27$ & $8.8 \pm 0.19$ & $0.3 \pm 0.21$ & $10.4 \pm 0.16$ & $8.9 \pm 0.41$ & $7.8 \pm 0.41$ \\
\hline DSS (7 days) & $24.1 \pm 0.79$ & $24.1 \pm 0.80$ & $-0.03 \pm 0.14$ & $7.9 \pm 0.16$ & $6.9 \pm 1.22$ & $10.6 \pm 0.25$ & $10.0 \pm 0.52$ & $8.6 \pm 0.41$ \\
\hline DSS (17 days) & $23.9 \pm 0.51$ & $22.3 \pm 0.60$ & $-1.6 \pm 0.56$ & $6.9 \pm 0.22$ & $25.9 \pm 1.6$ & $9.5 \pm 0.11$ & $10.2 \pm 0.47$ & $8.2 \pm 0.36$ \\
\hline $5-\mathrm{ASA}$ at $25 \mathrm{mg} / \mathrm{kg}$ & $24.9 \pm 0.49$ & $23.2 \pm 0.68$ & $-1.6 \pm 0.52$ & $7.4 \pm 0.13$ & $19.4 \pm 2.46$ & $9.9 \pm 0.29$ & $5.2 \pm 0.60$ & $3.6 \pm 0.52$ \\
\hline $5-\mathrm{ASA}$ at $50 \mathrm{mg} / \mathrm{kg}$ & $25.6 \pm 0.42$ & $24.5 \pm 0.43$ & $-1.1 \pm 0.3$ & $7.5 \pm 0.18$ & $18.7 \pm 2.03$ & $9.8 \pm 0.33$ & $6.4 \pm 0.35$ & $3.9 \pm 0.25$ \\
\hline 5-ASA at $75 \mathrm{mg} / \mathrm{kg}$ & $22.6 \pm 0.73$ & $21.8 \pm 0.39$ & $-0.8 \pm 0.57$ & $7.6 \pm 0.23$ & $13.3 \pm 2.36$ & $10.5 \pm 0.13$ & $6.4 \pm 0.63$ & $4.5 \pm 0.43$ \\
\hline $\begin{array}{l}\text { Olsalazine + Cyclosporine A } \\
\text { at } 25 \mathrm{mg} / \mathrm{kg}\end{array}$ & $23.7 \pm 0.54$ & $23.8 \pm 0.63$ & $0.1 \pm 0.17$ & $7.8 \pm 0.12$ & $12.9 \pm 2.18$ & $9.9 \pm 0.22$ & $7.5 \pm 0.44$ & $6.1 \pm 0.32$ \\
\hline $\begin{array}{l}\text { Olsalazine + Cyclosporine A } \\
\text { at } 50 \mathrm{mg} / \mathrm{kg}\end{array}$ & $24.4 \pm 0.33$ & $25 \pm 0.39$ & $0.6 \pm 0.22$ & $8.1 \pm 0.25$ & $12.1 \pm 1.1$ & $10.3 \pm 0.16$ & $7.6 \pm 0.54$ & $6.4 \pm 0.41$ \\
\hline $\begin{array}{l}\text { Olsalazine + Cyclosporine A } \\
\text { at } 75 \mathrm{mg} / \mathrm{kg}\end{array}$ & $22.4 \pm 0.35$ & $22.8 \pm 0.25$ & $0.4 \pm 0.19$ & $8.1 \pm 0.23$ & $12.1 \pm 1.68$ & $10.4 \pm 0.14$ & $6.0 \pm 0.41$ & $5.0 \pm 0.39$ \\
\hline $\mathrm{Cl}$-Amidine at $25 \mathrm{mg} / \mathrm{kg}$ & $25.4 \pm 0.57$ & $26 \pm 0.70$ & $0.7 \pm 0.55$ & $7.9 \pm 0.17$ & $17.5 \pm 2.18$ & $9.2 \pm 0.23$ & $7.9 \pm 0.52$ & $6.3 \pm 0.46$ \\
\hline $\mathrm{Cl}$-Amidine at $50 \mathrm{mg} / \mathrm{kg}$ & $24.6 \pm 0.46$ & $26 \pm 0.46$ & $1.4 \pm 0.33$ & $8.5 \pm 0.27$ & $13.1 \pm 2$ & $9.4 \pm 0.27$ & $7.5 \pm 0.38$ & $6.3 \pm 0.35$ \\
\hline Cl-Amidine at $75 \mathrm{mg} / \mathrm{kg}$ & $25.0 \pm 0.74$ & $26.1 \pm 0.60$ & $1.1 \pm 0.37$ & $8.3 \pm 0.14$ & $11.9 \pm 1.54$ & $9.5 \pm 0.28$ & $8.1 \pm 0.55$ & $6.5 \pm 0.41$ \\
\hline BB-Cl-Amidine at $0.1 \mathrm{mg} / \mathrm{kg}$ & $24.3 \pm 0.38$ & $23.7 \pm 0.34$ & $-0.6 \pm 0.39$ & $8.2 \pm 0.30$ & $16.1 \pm 1.40$ & $9.1 \pm 0.19$ & $7.6 \pm 1.00$ & $6.2 \pm 0.63$ \\
\hline BB-Cl-Amidine at $0.2 \mathrm{mg} / \mathrm{kg}$ & $25.0 \pm 0.80$ & $24.6 \pm 0.64$ & $-0.4 \pm 0.25$ & $8.1 \pm 0.17$ & $14.4 \pm 1.96$ & $8.3 \pm 0.32$ & $8.1 \pm 0.95$ & $6.4 \pm 0.72$ \\
\hline BB-Cl-Amidine at $1 \mathrm{mg} / \mathrm{kg}$ & $25.1 \pm 0.38$ & $26.4 \pm 0.56$ & $1.3 \pm 0.35$ & $7.5 \pm 0.33$ & $9.6 \pm 0.30$ & $9.0 \pm 0.68$ & $8.6 \pm 1.05$ & $7.2 \pm 0.87$ \\
\hline Quinacrine at $25 \mathrm{mg} / \mathrm{kg}$ & $25.3 \pm 0.32$ & $24.7 \pm 0.37$ & $-0.7 \pm 0.38$ & $8.1 \pm 0.15$ & $9 \pm 1.97$ & $10.0 \pm 0.32$ & $6.4 \pm 0.0 .47$ & $4.5 \pm 0.39$ \\
\hline Quinacrine at $50 \mathrm{mg} / \mathrm{kg}$ & $24.8 \pm 0.46$ & $23.4 \pm 0.88$ & $-0.9 \pm 0.7$ & $8.6 \pm 0.30$ & $8.7 \pm 2.24$ & $9.9 \pm 0.16$ & $6.0 \pm 0.32$ & $4.3 \pm 0.38$ \\
\hline Quinacrine at $75 \mathrm{mg} / \mathrm{kg}$ & $24.9 \pm 0.69$ & $24.0 \pm 0.55$ & $-1.0 \pm 0.24$ & $8.0 \pm 0.12$ & $8.3 \pm 1.08$ & $10.1 \pm 0.25$ & $4.6 \pm 0.59$ & $2.8 \pm 0.48$ \\
\hline AG at $25 \mathrm{mg} / \mathrm{kg}$ & $22.7 \pm 0.45$ & $23.2 \pm 0.85$ & $0.5 \pm 0.55$ & $7.6 \pm 0.31$ & $14.6 \pm 2.63$ & $10.2 \pm 0.15$ & $9.1 \pm 0.59$ & $7.6 \pm 0.40$ \\
\hline AG at $50 \mathrm{mg} / \mathrm{kg}$ & $24.6 \pm 0.22$ & $25.3 \pm 0.32$ & $0.8 \pm 0.3$ & $7.7 \pm 0.21$ & $13.8 \pm 2.31$ & $10.0 \pm 0.17$ & $8.1 \pm 0.44$ & $6.3 \pm 0.35$ \\
\hline AG at $75 \mathrm{mg} / \mathrm{kg}$ & $24.7 \pm 0.68$ & $25.3 \pm 0.86$ & $0.6 \pm 0.44$ & $8.2 \pm 0.6$ & $10.8 \pm 1.71$ & $9.4 \pm 0.19$ & $9.1 \pm 0.50$ & $7.3 \pm 0.51$ \\
\hline $\mathrm{HAG}$ at $25 \mathrm{mg} / \mathrm{kg}$ & $24.2 \pm 0.40$ & $23.5 \pm 0.84$ & $-0.7 \pm 0.81$ & $6.9 \pm 0.16$ & $17.1 \pm 1.79$ & $9.7 \pm 0.29$ & $7.7 \pm 0.77$ & $5.9 \pm 0.75$ \\
\hline $\mathrm{HAG}$ at $50 \mathrm{mg} / \mathrm{kg}$ & $24.9 \pm 0.66$ & $24.9 \pm 0.64$ & $0 \pm 0.24$ & $8.2 \pm 0.37$ & $13.5 \pm 1.71$ & $9.9 \pm 0.21$ & $6.8 \pm 0.52$ & $5.1 \pm 0.37$ \\
\hline $\mathrm{HAG}$ at $75 \mathrm{mg} / \mathrm{kg}$ & $23.6 \pm 0.44$ & $24.0 \pm 0.52$ & $0.4 \pm 0.39$ & $7.5 \pm 0.19$ & $8.3 \pm 1.19$ & $9.8 \pm 0.29$ & $7.7 \pm 0.60$ & $6.4 \pm 0.59$ \\
\hline Resveratrol at $25 \mathrm{mg} / \mathrm{kg}$ & $23.8 \pm 0.49$ & $24.0 \pm 0.47$ & $0.2 \pm 0.34$ & $7.4 \pm 0.21$ & $15.3 \pm 1.89$ & $9.7 \pm 0.17$ & $7.5 \pm 0.22$ & $6.4 \pm 0.17$ \\
\hline Resveratrol at $50 \mathrm{mg} / \mathrm{kg}$ & $23.9 \pm 0.42$ & $24.3 \pm 0.39$ & $0.4 \pm 0.61$ & $7.2 \pm 0.18$ & $8.7 \pm 0.97$ & $9.1 \pm 0.64$ & $5.5 \pm 0.49$ & $4.5 \pm 0.42$ \\
\hline Resveratrol at $75 \mathrm{mg} / \mathrm{kg}$ & $23.8 \pm 0.32$ & $24.4 \pm 0.39$ & $0.6 \pm 0.31$ & $7.5 \pm 0.28$ & $7.2 \pm 1.24$ & $9.9 \pm 0.24$ & $6.7 \pm 0.67$ & $5.5 \pm 0.64$ \\
\hline
\end{tabular}

Values are group averages $\pm \mathrm{SE}$.

WBC, white blood cells. RBC, Red Blood Cells.

$\uparrow$ Millions per cubic milliliter of blood.

$\dagger \dagger$ Billions per cubic milliliter of blood.

inflammatory stress, and ulceration, we also used this parameter as an indicator of inflammation severity (Figure 2 , Table 1). The average colon length of the water control group was $8.8 \pm 0.2 \mathrm{~cm}$. DSS treatment caused colon shrinkage to $7.9 \pm 0.2 \mathrm{~cm}$ on average at day 7 , and further to $6.9 \pm 0.20 \mathrm{~cm}$ at the 17 day time point. In contrast, the average colon length for all tested drugs at the day 17 time point varied from $7.4 \pm 0.1 \mathrm{~cm}$ for the lowest used concentration of 5-ASA to $8.6 \pm 0.3 \mathrm{~cm}$ for the middle concentration of quinacrine, which is within the range of colons lengths found in healthy control animals. The compounds ranged in the following order from the most to the least effective in preventive colon shrinkage: Quinacrine $>\mathrm{Cl}$-Amidine $>\mathrm{HAG}>\mathrm{BB}$-Cl-Amidine $>A G$ $>$ Olsalazine + Cyclosporine A combination > 5-ASA > Resveratrol. In general, all tested compounds beat current FDA-approved treatment strategies in their efficacy. These results are consistent with histological inflammatory scores for the tested groups. Surprisingly, animals treated with resveratrol, which demonstrated the lowest immunological scores, had relatively shorter colons, but the colons were still significantly longer, than those of DSS only treated animals. It is also worth mentioning that the middle doses of most tested compounds were more effective than both lower and higher doses used, in regard to colon shrinkage prevention.

An additional parameter - difference in animal body weight on day 17 (last experimental day) in comparison to the day 0 (experiment starting day) - was used to assess the overall health of the mice at the end of experiment (Figure 3, Table 1), as well as potential toxicity of the tested drugs. On average, the water control group of healthy animals gained $1.8 \mathrm{~g}$ of body weight during the course of experiment, whereas the DSS only treated group lost almost the same amount of body weight $(-1.6 \mathrm{~g})$. The FDA-approved anti-colitis drug 5-ASA demonstrated comparable weight loss to the DSS only group, ranging from $0.8 \mathrm{~g}$ to $1.6 \mathrm{~g}$ depending on the dose used, whereas animals treated with another FDA-approved combination of Olsalazine + Cyclosporine A showed a moderate weight increase of $0.1-0.6 \mathrm{~g}$ depending on the doses used. The weight change dynamic was markedly different 


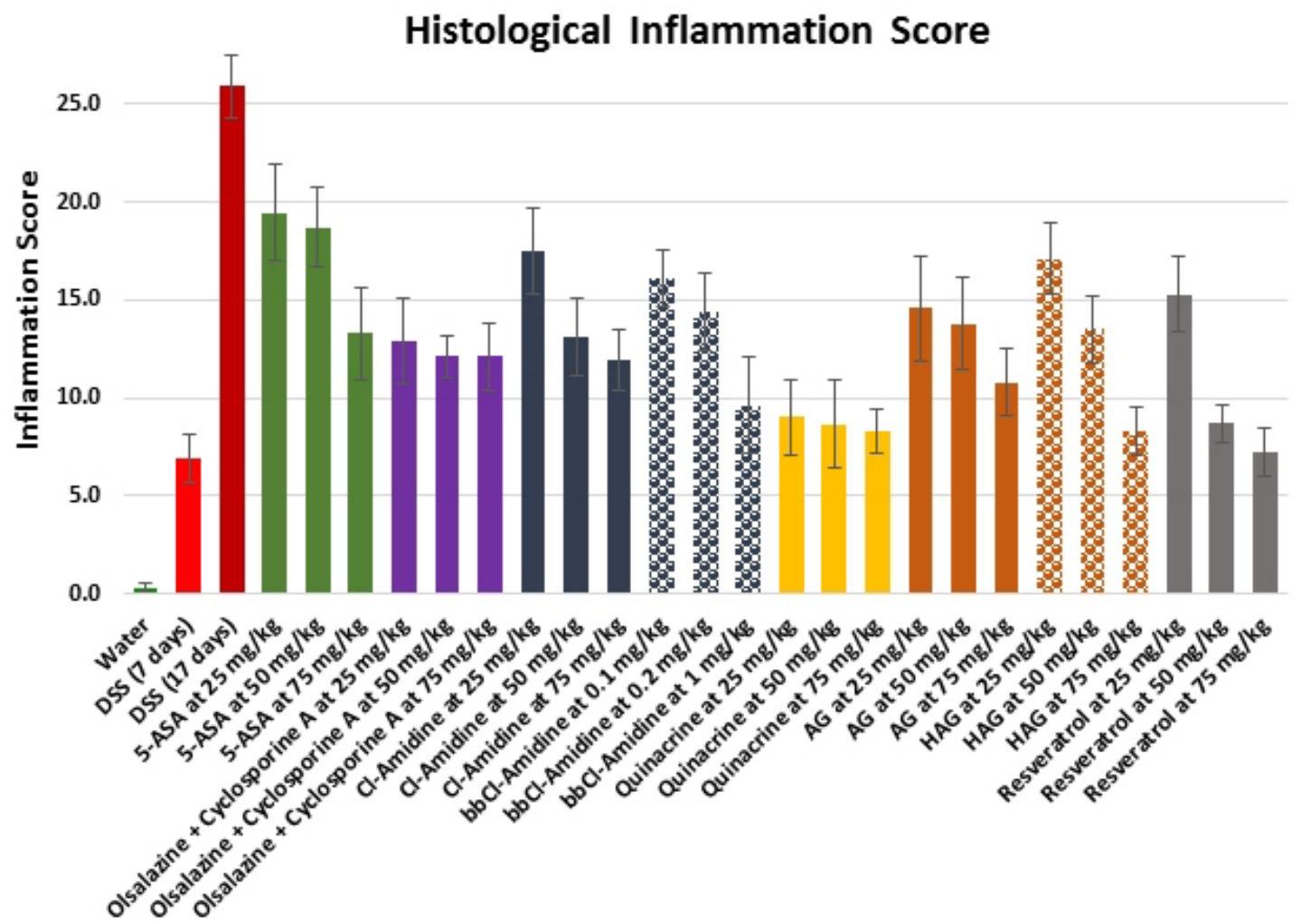

Figure 1: Effects of the treatment on histological inflammation score in the DSS model of colitis. Values represent mean \pm S.E. The differences between experimental groups and 17 days DSS only group were statistically significant for all groups $(p<0.05)$.

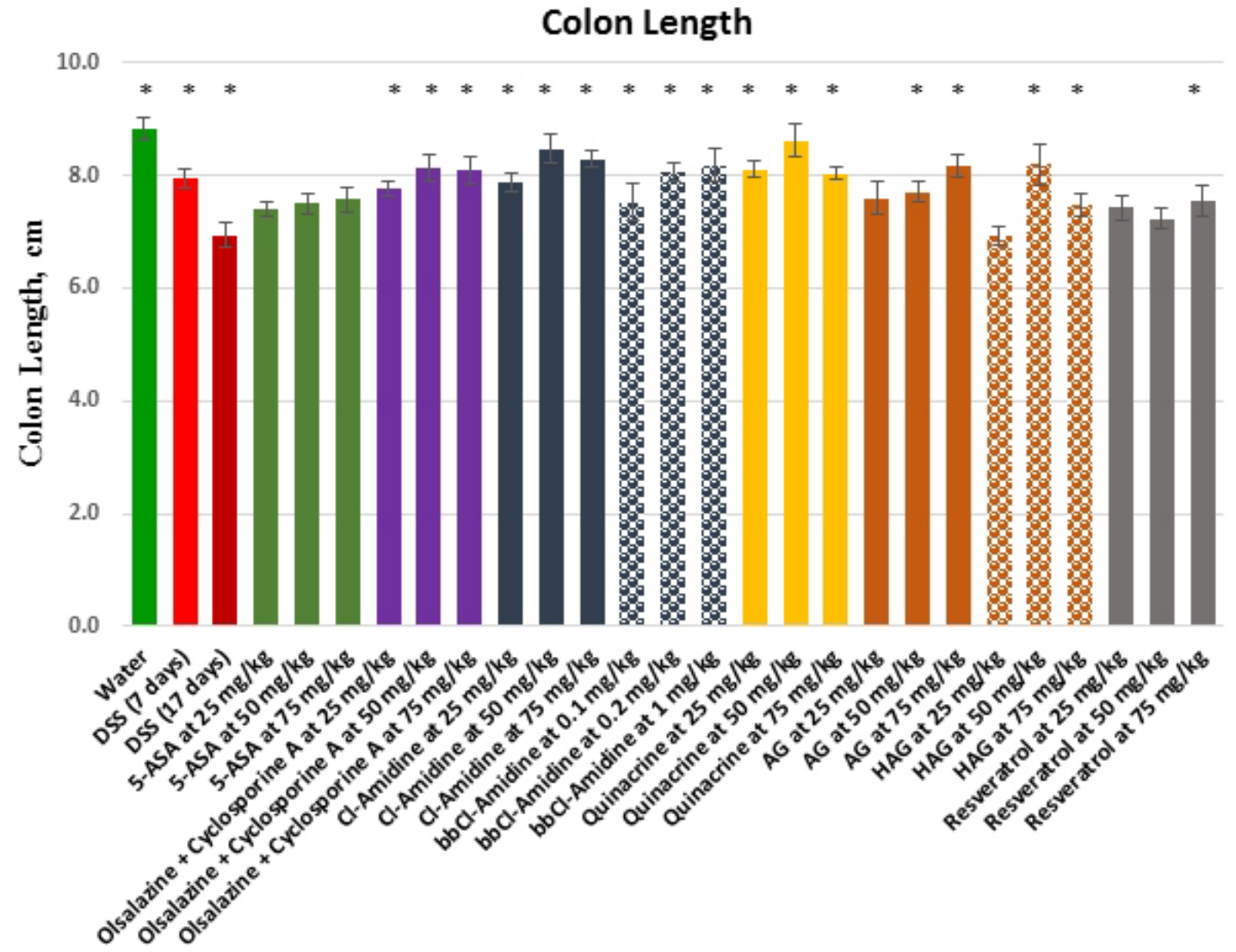

Figure 2: Effects of the treatment on colon length in the DSS model of colitis. Values represent mean \pm S.E. * indicates significant difference $(p<0.05)$ from 17 days DSS only group. 
for all tested compounds. While animals treated with the small molecule compound Cl-Amidine gained weight comparable to the water group $(0.7-1.4 \mathrm{~g})$ at all used doses, its derivative, BB-Cl-Amidine, caused weight loss at lower and middle doses, but one of the largest weight gains for the highest used dose $-1.3 \mathrm{~g}$ for the 1 $\mathrm{mg} / \mathrm{kg}$ dose. CAM compounds were also varied in this regard. AG caused a substantial dose-dependent weight gain of $0.5-0.8 \mathrm{~g}$, while only the highest dose of HAG allowed the animals to gain weight. Resveratrol caused a moderate dose-dependent body weight increase of 0.2 $0.6 \mathrm{~g}$, similar to the AG and Olsalazine + Cyclosporine A groups. The overall order of the compounds from the most to the least effective in regards of helping to maintain body weight and overall well-being was as follows: $\mathrm{Cl}$-Amidine $>B B-C l$-Amidine $>A G>$ Resveratrol $>$ Olsalazine + Cyclosporine $A>H A G>$ Quinacrine $>5-A S A$. Once again, CAM and small molecule compounds tested here prevail over current FDA-approved colitis therapeutics.

\section{Inflammatory stress is reduced in treated mice}

We have previously shown that all compounds tested here can be used to prevent and treat mouse colitis [14-16, $18,29,41-45]$ through, at least partially, the induction of inflammatory cell apoptosis mechanism [14, 42].
To further compare the efficacy of tested compounds, we examined the expression of an inflammatory marker, COX-2, using IHC. Since the histological inflammation scores showed unconditional dose dependence for all tested compounds, only the colons of animals treated with the highest doses of each compound were used for IHC. Figure 4 demonstrates the quantification results of IHC staining with COX-2. Images of representative colon sections are shown in Supplementary Picture 1. Overall, COX-2 levels were elevated in the DSS only treated mice, and were statistically significantly reduced in all treatment groups in the following order, complementing histopathology results: Resveratrol $>$ Quinacrine $>B B$ Cl-Amidine $>A G>H A G>$ Olsalazine + Cyclosporine $A$ $>$ 5-ASA $>C l$-Amidine.

Similarly, the total white blood cell (WBC) count and lymphocyte count in particular, reflecting systemic inflammation load, was increased in DSS only treated groups, but significantly reduced in the treatment groups (Table 1). There was no significant difference in red blood cell (RBC) count for all groups, thereby excluding any anemia-like conditions in the treatment groups. Overall, these results are consistent with the notion that all used treatment agents and conditions suppress DSS-induced colitis in a dose dependent manner.

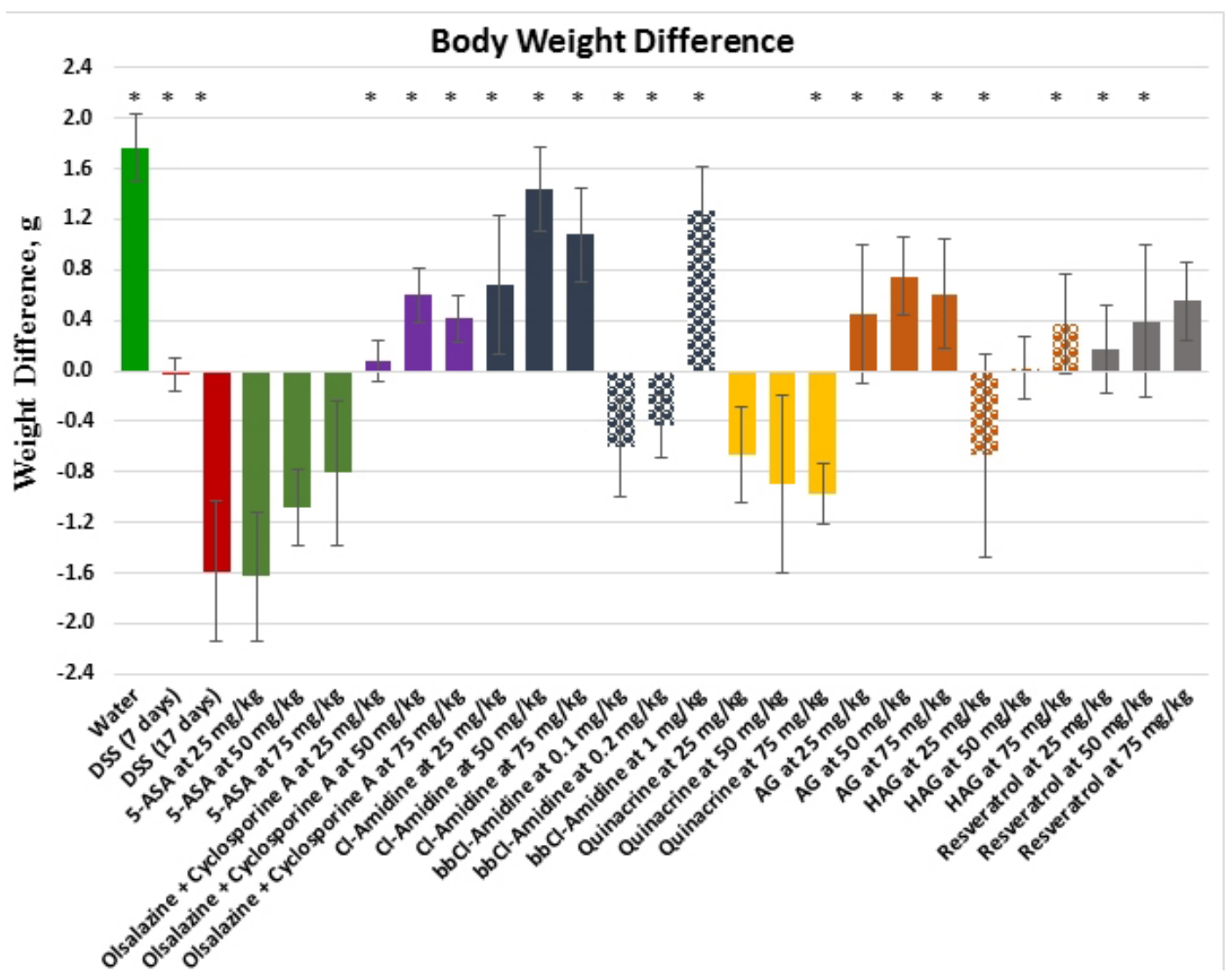

Figure 3: Body weight difference after the treatment in the DSS model of colitis. Values represent mean \pm S.E. * indicates significant difference $(p<0.05)$ from 17 days DSS only group. 


\section{DISCUSSION}

The objective of this study was to rank eight treatments in regard to their anti-colitis efficiency in a DSS mouse model. In order to do so, we quantitatively assessed four endpoints - histological inflammation scores, colon lengths, body weight changes, and immunoreactivity scores for the COX-2 marker of inflammation. Also we demonstrate a very similar ranking order for the tested compounds, although there were some serious variations in this order in regards to each endpoint. For instance, quinacrine at the dose of $75 \mathrm{mg} / \mathrm{kg}$ was ranked $\# 1$ or $\# 2$ in all but one category - body weight loss, in which it was one of the worst compounds. This type of rank differences prevented us from drawing a direct conclusion about the potency of each compound in the treatment of colitis. Therefore we have developed a novel tool - composite scoring - that combines all measured endpoint parameters.

We first ranked each of the endpoint measurements in order of primary importance (levels of inflammation and the COX-2 IRS) and secondary, but nonetheless also of vital importance (colon length and body weight difference). This final composite score primarily relies on the two primary endpoint measurements. However, if the secondary measurements are highly different from what is expected under the water only control group, which is considered the golden health standard, this will increase the composite score. Two tuning parameters are introduced: the first controls the threshold of how different the secondary scores need to be from the water group before contributing to the composite score, and the second is the magnitude of the penalty that is levied from these secondary endpoints. These tuning parameters are then chosen such that the treatment groups are most different from each other, measured by the F-statistic arising from the one-way analysis of variance of the composite scores. On the basis of these approaches and using a multiple comparisons procedure with a Benjamini-Hochberg false discovery rate correction, the eleven treatment protocols are ranked and grouped as indicated below, with those in the same group not significantly different from each other at 5\% level of significance. Details of the statistical analysis approach leading to the final ranking provided here will be published separately.

Using this approach, we were able to rank all tested compounds based on composite score in the following order:

Resveratrol $>$ BB-Cl-Amidine $\geq$ Quinacrine $>$ HAG $>$ AG $>$ Cl-Amidine $>$ Olsalazine + Cyclosporine A > 5-ASA.

Overall, all tested CAM and small molecule compounds were more effective against colitis than current FDA-approved anti-colitis treatments, with resveratrol on top of the list and 5-ASA at the bottom.

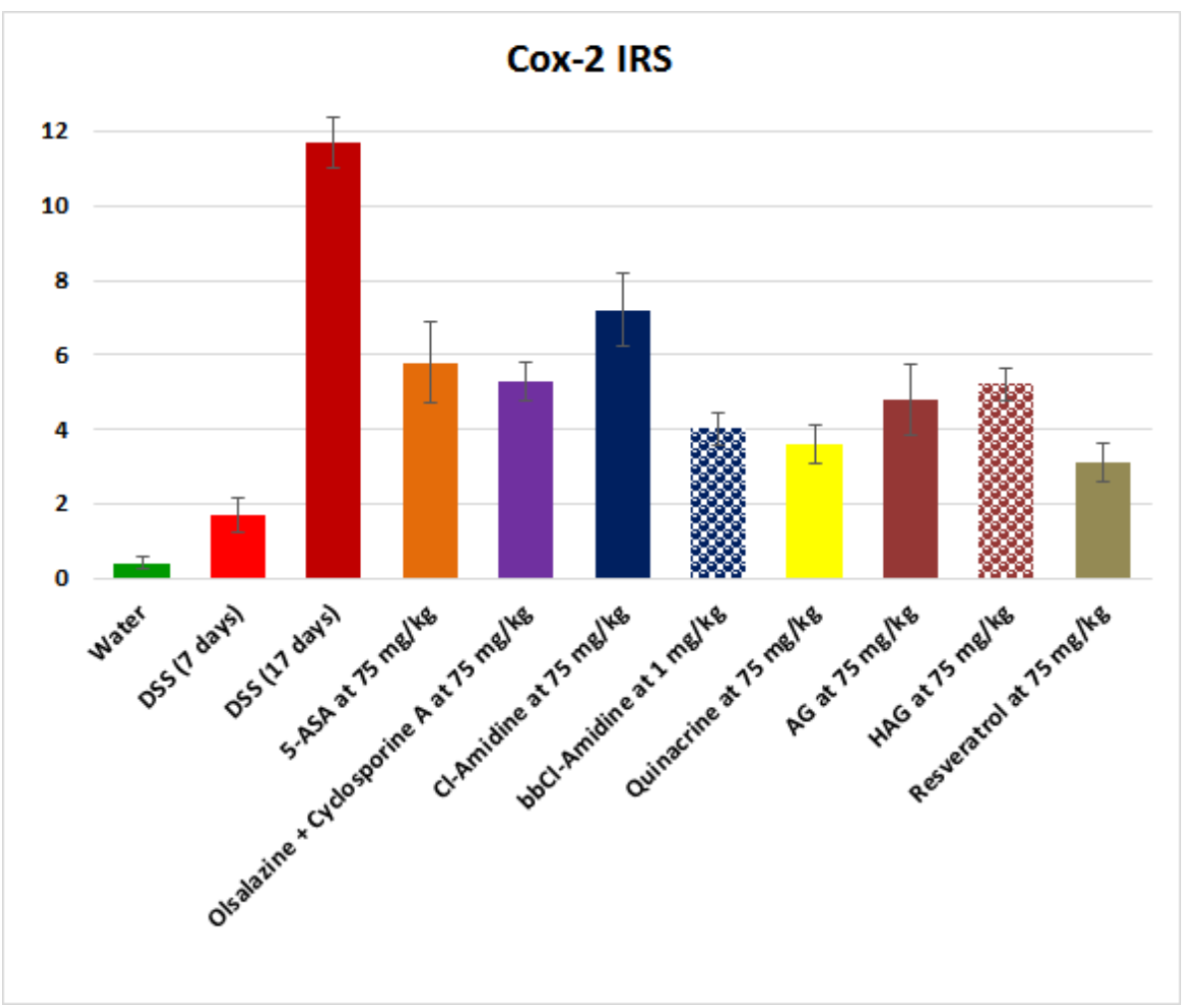

Figure 4: Effects of the treatment on the colon Cox-2 immunoreactivity score in the DSS model of colitis. Values represent the average scores for each group \pm S.E. ( $N=10$ per group). The differences between individual experimental groups and 17 days DSS only group were statistically significant $(p<0.05)$ for all groups. 
These results are consistent with our conclusions drawn for each endpoint. However there are some interesting exceptions. Quinacrine, which was ranked as one of the top two compounds in regard to each endpoint, except for body weight change, was ranked \#3 overall, surprisingly losing its place to $\mathrm{BB}-\mathrm{Cl}$-Amidine that demonstrated rather mediocre results in regard to each endpoint.

The results of this study provide a useful multicomparisons procedure composite score to assess biological potency of different compounds, as well as pre-clinical data for the movement of specific treatments examined here to clinical trials.

\section{MATERIALS AND METHODS}

\section{Chemicals and reagents}

Olsalazine sodium was purchased from Selleckchem (USA), 5-Aminosalicylic acid (5-ASA) and resveratrol from Acros Organics (USA), and Cyclosporine A - from Santa Cruz Biotech (USA). Quinacrine dihydrochloride was obtained from Sigma (USA), and dextran sulfate sodium (molecular weight, 36,000-50,000) was purchased from Advanced Technology \& Industrial Co., Ltd. (Hong Kong).

The synthesis of $\mathrm{Cl}$-amidine has been described previously $[20,46]$, as well as its modified version, BBCl-Amidine [23]. The American Ginseng (AG) Panax quinquefolius extract has been described previously in detail by our laboratory [14], as well, as we have recently described the generation of the Hexane fraction of $A G$ (HAG) [44].

\section{Animals and DSS mouse model of colitis}

Male C57BL/6 mice, 12 weeks of age, weighing 20 to $29 \mathrm{~g}$ were obtained from The Jackson Laboratories (Bar Harbor, ME). All mice were kept in clean, dedicated animal quarters and provided food and water. Care and use of animals was overseen by the Animal Resource Facility (ARF) of the University of South Carolina under the direction of a veterinarian. The ARF is fully accredited by the Association for Assessment and Accreditation of Laboratory Animal Care International, is registered with the U.S. Department of Agriculture (56-R-003) and has an active letter of Assurance of Compliance on file at the NIH. The Institutional Animal Care and Use Committee (IACUC) of the University of South Carolina approved this study.

The DSS mouse model of colitis used here is similar to the one used previously by our lab [29, 40]. Animals received either water or $1.5 \%$ DSS dissolved in water for 7 days. Seven days after the initial DSS treatment, we sacrificed 10 animals to monitor colitis progression, and for the rest of the animals (10 mice per group) initiated a daily oral administration of the following agents:

Vehicle solution

5-ASA at 25, 50, or $75 \mathrm{mg} / \mathrm{kg}$;

Olsalazine at $100 \mathrm{mg} / \mathrm{kg}$ in combination with 25, 50, or $75 \mathrm{mg} / \mathrm{kg}$ of Cyclosporin A;

Cl-Amidine at 25,50 , or $75 \mathrm{mg} / \mathrm{kg}$;

BB-Cl-Amidine at $0.1,0.2$, or $1 \mathrm{mg} / \mathrm{kg}$;

Quinacrine at 25, 50, or $75 \mathrm{mg} / \mathrm{kg}$;

$\mathrm{AG}$ at 25,50 , or $75 \mathrm{mg} / \mathrm{kg}$;

$\mathrm{HAG}$ at 25,50 , or $75 \mathrm{mg} / \mathrm{kg}$;

Resveratrol at 25,50 , or $75 \mathrm{mg} / \mathrm{kg}$.

All agents were administered by oral gavage once daily, except for Cl-Amidine and BB-Cl-Amidine, which were dissolved in the drinking water and available to the mice ad libitum. 1.5\% DSS treatment continued in the indicated groups. Water group of animals did not receive any DSS, nor treatment compounds. Control animals have received a vehicle solution as a treatment.

The doses of all agents were chosen based on the following criteria:

a. being in the range taken by humans;

b. being non-toxic; and

c. known to suppress colitis in mice based on previously published studies [14-16, 18, 29, 41-45].

Following 10 days of treatment with the above indicated compounds, on day 17 the mice were sacrificed and the colons were harvested for further processing and analysis. Blood was collected prior to the sacrifice. Colons were transected longitudinally, pinned open, and rinsed with PBS. Colon lengths were recorded, and colons were processed for hematoxylin-eosin (H\&E) staining and immunohistochemistry by fixing in formalin overnight, then Swiss-rolling and embedding in paraffin.

\section{Quantification of inflammation}

Sectioned colon samples were stained with H\&E. The sections were microscopically examined for histopathological changes using the following scoring system. Histology score was determined by two blinded investigators ( $\mathrm{AC}$ and $\mathrm{EW}$ ) as a product of multiplication for each of the three histological features by the percent area of involvement [42, 47]. Inflammation severity was scored as 0 for none, 1 for minimal, 2 for moderate, and 3 for severe; inflammation extent as 0 for none, 1 for mucosa, 2 for mucosa and submucosa, and 3 for transmural; crypt damage as 0 for none, 1 for one-third of crypt damaged, 2 for two-thirds of crypt damaged, 3 for crypt loss and surface epithelium intact, 4 for crypt loss and surface epithelium loss; and percent area involvement was scored as 0 for $0 \%, 1$ for $1-25 \%, 2$ for $26-50 \%, 3$ for $51-75 \%$, and 4 for $76-100 \%$. Therefore, the minimum score is 0 , and the maximum score is 40 . 


\section{Immunohistochemical staining}

For immunohistochemical staining, formalin-fixed, paraffin-embedded serial sections of mouse colon tissues were incubated overnight with antibodies against Cox2 (polyclonal, 1:2000 dilution; Cayman Chemical) by slow rocking using the Antibody Amplifier (ProHisto, Columbia, SC) to ensure even staining and reproducible results. After incubation with primary antibodies, sections were processed using EnVision+ System-HRP kits (DakoCytomation, Carpinteria, CA) according to kit protocols. The chromogen was diaminobenzidine, and sections were counterstained with $1 \%$ methyl green. Intensity and degree of staining were evaluated independently by three blinded investigators (AC, AC and EW). For each tissue section, the percentage of positive cells was scored on a scale of $0-5$ for the percentage of tissue stained: 0 ( $0 \%$ positive cells), $1(<10 \%), 2(11-$ $25 \%), 3(26-50 \%), 4(51-80 \%)$, or $5(>80 \%)$. Staining intensity was scored on a scale of 0-3: 0 (negative staining), 1 (weak staining), 2 (moderate staining), or 3 (strong staining). The two scores were multiplied, resulting in an immunoreactivity score (IRS) value ranging from 0 to 15 .

\section{Statistics}

Mean differences between groups were compared by one-way ANOVA with Scheffé's multiple comparison tests. A Pearson correlation coefficient was applied for comparisons of the trends. $P \leq 0.05$ was chosen for significance.

A statistical analysis that allowed final ranking of the compounds' overall anti-colitis effectiveness based on a composite score was done using a multiple comparisons procedure with a Benjamini-Hochberg false discovery rate correction which will be fully described and discussed in a separate paper.

\section{Abbreviations}

5-ASA, 5-aminosalicylic acid; AG, American Ginseng; CAM, complementary and alternative medicine; DSS, dextran sulfate sodium; HAG, hexane fraction of AG; H\&E, hematoxylin and eosin; IBD, inflammatory bowel disease; IHC, immunohistochemistry; IRS, immunoreactivity score; PAD, protein arginine deiminase; UC, ulcerative colitis.

\section{ACKNOWLEDGMENTS}

We thank Tia Davis and Sapana Shah at the University of South Carolina animal facility for the technical assistance in blood collection.

\section{CONFLICT OF INTEREST}

There is no conflict of interest.

\section{GRANT SUPPORT}

This work was supported by National Institutes of Health Center for Colon Cancer Research, NIH grant 1R03CA171326 (LH), the Core facilities in the National Institutes of Health Center for Colon Cancer Research Grant 5P20 RR-017698-08 (LH), NCCAM, NIH 2 P01 AT003961-06A1 (PN), and University of South Carolina Electronic Research Administration, USCeRA grant 11110-15-38752 (AC).

\section{Editorial note}

This paper has been accepted based in part on peer review conducted by another journal and the authors' response and revisions as well as expedited peer-review in Oncotarget.

\section{REFERENCES}

1. Itzkowitz $\mathrm{SH}$ and Yio X. Inflammation and cancer IV. Colorectal cancer in inflammatory bowel disease: the role of inflammation. Am J Physiol Gastrointest Liver Physiol. 2004; 287:G7-17.

2. Ekbom A, Helmick C, Zack M and Adami HO. Ulcerative colitis and colorectal cancer. A population-based study. N Engl J Med. 1990; 323:1228-1233.

3. Askling J, Dickman PW, Karlen P, Brostrom O, Lapidus A, Lofberg R and Ekbom A. Colorectal cancer rates among first-degree relatives of patients with inflammatory bowel disease: a population-based cohort study. Lancet. 2001; 357:262-266.

4. Rubin DT, Cruz-Correa MR, Gasche C, Jass JR, Lichtenstein GR, Montgomery EA, Riddell RH, Rutter MD, Ullman TA, Velayos FS and Itzkowitz S. Colorectal cancer prevention in inflammatory bowel disease and the role of 5-aminosalicylic acid: a clinical review and update. Inflamm Bowel Dis. 2008; 14:265-274.

5. Kruis W, Schreiber S, Theuer D, Brandes JW, Schutz E, Howaldt S, Krakamp B, Hamling J, Monnikes H, Koop I, Stolte M, Pallant D and Ewald U. Low dose balsalazide ( $1.5 \mathrm{~g}$ twice daily) and mesalazine ( $0.5 \mathrm{~g}$ three times daily) maintained remission of ulcerative colitis but high dose balsalazide ( $3.0 \mathrm{~g}$ twice daily) was superior in preventing relapses. Gut. 2001; 49:783-789.

6. Sandborn WJ, Feagan BG and Lichtenstein GR. Medical management of mild to moderate Crohn's disease: 
evidence-based treatment algorithms for induction and maintenance of remission. Aliment Pharmacol Ther. 2007; 26:987-1003.

7. Siegel CA, Marden SM, Persing SM, Larson RJ and Sands BE. Risk of lymphoma associated with combination antitumor necrosis factor and immunomodulator therapy for the treatment of Crohn's disease: a meta-analysis. Clin Gastroenterol Hepatol. 2009; 7:874-881. Epub 2009 Jan 2024.

8. Domm S, Cinatl J and Mrowietz U. The impact of treatment with tumour necrosis factor-alpha antagonists on the course of chronic viral infections: a review of the literature. Br J Dermatol. 2008; 159:1217-1228. Epub 2008 Sep 1225.

9. Lichtenstein GR, Abreu MT, Cohen R and Tremaine W. American Gastroenterological Association Institute technical review on corticosteroids, immunomodulators, and infliximab in inflammatory bowel disease. Gastroenterology. 2006; 130:940-987.

10. Shepela $C$. The safety of biologic agents in the treatment of inflammatory bowel disease. Minn Med. 2008; 91:42-45.

11. Kwon JH and Farrell RJ. The risk of lymphoma in the treatment of inflammatory bowel disease with immunosuppressive agents. Crit Rev Oncol Hematol. 2005; 56:169-178.

12. Loftus CG, Egan LJ and Sandborn WJ. Cyclosporine, tacrolimus, and mycophenolate mofetil in the treatment of inflammatory bowel disease. Gastroenterol Clin North Am. 2004; 33:141-169, vii.

13. Ichikawa T, Li J, Nagarkatti P, Nagarkatti M, Hofseth LJ, Windust A and Cui T. American ginseng preferentially suppresses STAT/iNOS signaling in activated macrophages. Journal of ethnopharmacology. 2009; 125:145-150.

14. Jin Y, Kotakadi VS, Ying L, Hofseth AB, Cui X, Wood PA, Windust A, Matesic LE, Pena EA, Chiuzan C, Singh NP, Nagarkatti M, Nagarkatti PS, Wargovich MJ and Hofseth LJ. American ginseng suppresses inflammation and DNA damage associated with mouse colitis. Carcinogenesis. 2008; 29:2351-2359. Epub 2008 Sep 2318.

15. Poudyal D, Cui X, Le P, Hofseth A, Windust A, Nagarkatti M, Nagarkatti P, Schetter A, Harris C and Hofseth L. A key role of microRNA-29b for the suppression of colon cancer cell migration by American Ginseng. PLoS One. 2013; 8:e75034.

16. Cui X, Jin Y, Hofseth AB, Pena E, Habiger J, Chumanevich A, Poudyal D, Nagarkatti M, Nagarkatti PS, Singh UP and Hofseth LJ. Resveratrol suppresses colitis and colon cancer associated with colitis. Cancer Prev Res. 2010; 3:549-559. Epub 2010 Mar 2023.

17. Hofseth LJ, Singh UP, Singh NP, Nagarkatti $M$ and Nagarkatti PS. Taming the beast within: resveratrol suppresses colitis and prevents colon cancer. Aging (Albany NY). 2010; 2:183-184. doi: 10.18632/aging.100143.

18. Samadi AK, Bilsland A, Georgakilas AG, Amedei A,
Amin A, Bishayee A, Azmi AS, Lokeshwar BL, Grue B, Panis C, Boosani CS, Poudyal D, Stafforini DM, et al. A multi-targeted approach to suppress tumor-promoting inflammation. Seminars in cancer biology. 2015; 35 Suppl:S151-184.

19. Greten FR, Eckmann L, Greten TF, Park JM, Li ZW, Egan LJ, Kagnoff MF and Karin M. IKKbeta links inflammation and tumorigenesis in a mouse model of colitis-associated cancer. Cell. 2004; 118:285-296.

20. Causey CP and Thompson PR. An improved synthesis of haloaceteamidine-based inactivators of protein arginine deiminase 4 (PAD4). Tetrahedron Lett. 2008; 49:43834385.

21. Causey CP, Jones JE, Slack JL, Kamei D, Jones LE, Subramanian V, Knuckley B, Ebrahimi P, Chumanevich AA, Luo Y, Hashimoto H, Sato M, Hofseth LJ and Thompson PR. The development of N-alpha-(2-carboxyl) benzoyl-N(5)-(2-fluoro-1-iminoethyl)-1-ornithine amide (o-F-amidine) and N-alpha-(2-carboxyl)benzoyl-N(5)-(2chloro-1-iminoethyl)-1-ornithine amide (o-Cl-amidine) as second generation protein arginine deiminase (PAD) inhibitors. Journal of medicinal chemistry. 2011; 54:69196935.

22. Bicker KL, Anguish L, Chumanevich AA, Cameron MD, Cui X, Witalison E, Subramanian V, Zhang X, Chumanevic AP, Hofseth LJ, Coonrod SA and Thompson PR. D-Amino Acid-Based Protein Arginine Deiminase Inhibitors: Synthesis, Pharmacokinetics, and in Cellulo Efficacy. ACS Medicinal Chemistry. 2012; 3:1081-1085.

23. Knight JS, Subramanian V, O'Dell AA, Yalavarthi S, Zhao W, Smith CK, Hodgin JB, Thompson PR and Kaplan MJ. Peptidylarginine deiminase inhibition disrupts NET formation and protects against kidney, skin and vascular disease in lupus-prone MRL/lpr mice. Ann Rheum Dis. 2015; 74:2199-2206.

24. Chang X, Han J, Pang L, Zhao Y, Yang Y and Shen Z. Increased PADI4 expression in blood and tissues of patients with malignant tumors. BMC Cancer. 2009; 9:40.

25. Makrygiannakis D, af Klint E, Lundberg IE, Lofberg R, Ulfgren AK, Klareskog L and Catrina AI. Citrullination is an inflammation-dependent process. Ann Rheum Dis. 2006; 65:1219-1222. Epub 2006 Mar 1215.

26. Chang $X$ and Han J. Expression of peptidylarginine deiminase type 4 (PAD4) in various tumors. Mol Carcinog. 2006; 45:183-196.

27. Mohanan S, Cherrington $\mathrm{BD}$, Horibata S, McElwee JL, Thompson PR and Coonrod SA. Potential role of peptidylarginine deiminase enzymes and protein citrullination in cancer pathogenesis. Biochemistry research international. 2012; 2012:895343.

28. Witalison EE, Thompson PR and Hofseth LJ. Protein Arginine Deiminases and Associated Citrullination: Physiological Functions and Diseases Associated with Dysregulation. Current drug targets. 2015; 16:700-710. 
29. Chumanevich AA, Causey CP, Knuckley BA, Jones JE, Poudyal D, Chumanevich AP, Davis T, Matesic LE, Thompson PR and Hofseth LJ. Suppression of colitis in mice by $\mathrm{Cl}$-amidine: a novel peptidylarginine deiminase inhibitor. Am. 2011; 300:G929-938. Epub 2011 Mar 2017.

30. Cui X, Witalison EE, Chumanevich AP, Chumanevich AA, Poudyal D, Subramanian V, Schetter AJ, Harris CC, Thompson PR and Hofseth LJ. The induction of microRNA-16 in colon cancer cells by protein arginine deiminase inhibition causes a p53-dependent cell cycle arrest. PLoS One. 2013; 8:e53791. doi: 53710.51371/ journal.pone.0053791. Epub 0052013 Jan 0053797.

31. Witalison EE, Cui X, Hofseth AB, Subramanian V, Causey $\mathrm{CP}$, Thompson PR and Hofseth LJ. Inhibiting protein arginine deiminases has antioxidant consequences. The Journal of pharmacology and experimental therapeutics. 2015; 353:64-70.

32. Witalison EE, Cui X, Causey CP, Thompson PR and Hofseth LJ. Molecular targeting of protein arginine deiminases to suppress colitis and prevent colon cancer. Oncotarget. 2015; 6:36053-36062. doi: 10.18632/ oncotarget.5937.

33. Smithuis F, Kyaw MK, Phe O, Win T, Aung PP, Oo AP, Naing AL, Nyo MY, Myint NZ, Imwong M, Ashley E, Lee SJ and White NJ. Effectiveness of five artemisinin combination regimens with or without primaquine in uncomplicated falciparum malaria: an open-label randomised trial. Lancet. 10:673-681. Epub 2010 Sep 2019.

34. Smithuis F, Kyaw MK, Phe O, Win T, Aung PP, Oo AP, Naing AL, Nyo MY, Myint NZ, Imwong M, Ashley E, Lee SJ and White NJ. Effectiveness of five artemisinin combination regimens with or without primaquine in uncomplicated falciparum malaria: an open-label randomised trial. The Lancet Infectious diseases. 2010; 10:673-681

35. Gallant JN, Allen JE, Smith CD, Dicker DT, Wang W, Dolloff NG, Navaraj A and El-Deiry WS. Quinacrine synergizes with 5-fluorouracil and other therapies in colorectal cancer. Cancer. 2011; 12:239-251. Epub 2011 Aug 2011.

36. Toubi E, Rosner I, Rozenbaum M, Kessel A and Golan TD. The benefit of combining hydroxychloroquine with quinacrine in the treatment of SLE patients. Lupus. 2000; 9:92-95.

37. Tye MJ, White H, Appel B and Ansell HB. Lupus erythematosus treated with a combination of quinacrine, hydroxychloroquine and chloroquine. N Engl J Med. 1959; 260:63-66.

38. Wallace DJ. The use of quinacrine (Atabrine) in rheumatic diseases: a reexamination. Semin Arthritis Rheum. 1989; 18:282-296

39. Wallace DJ. Is there a role for quinacrine (Atabrine) in the new millennium? Lupus. 2000; 9:81-82.

40. Chumanevich AA, Witalison EE, Chaparala A,
Chumanevich A, Nagarkatti P, Nagarkatti M and Hofseth LJ. Repurposing the anti-malarial drug, quinacrine: new anti-colitis properties. Oncotarget. 2016; 7:52928-52939. doi: 10.18632/oncotarget.10608.

41. Jin Y, Hofseth AB, Cui X, Windust AJ, Poudyal D, Chumanevich AA, Matesic LE, Singh NP, Nagarkatti M, Nagarkatti PS and Hofseth LJ. American Ginseng Suppresses Colitis through p53-Mediated Apoptosis of Inflammatory Cells. Cancer Prev Res. 2010; 3:339-347.

42. Cui X, Jin Y, Poudyal D, Chumanevich AA, Davis T, Windust A, Hofseth A, Wu W, Habiger J, Pena E, Wood P, Nagarkatti M, Nagarkatti PS and Hofseth L. Mechanistic insight into the ability of American ginseng to suppress colon cancer associated with colitis. Carcinogenesis. 2010; 31:1734-1741.

43. Poudyal D, Le PM, Davis T, Hofseth AB, Chumanevich A, Chumanevich AA, Wargovich MJ, Nagarkatti M, Nagarkatti PS, Windust A and Hofseth LJ. A hexane fraction of American ginseng suppresses mouse colitis and associated colon cancer: anti-inflammatory and proapoptotic mechanisms. Cancer Prev Res (Phila). 2012; 5:685-696. doi: 610.1158/1940-6207.CAPR-1111-0421. Epub 2012 Jan 1131.

44. Poudyal D, Cui X, Mai Le P, Davis T, Hofseth AB, Jin Y, Chumanevich AA, Wargovich MJ, Nagarkatti M, Nagarkatti PS, Windust A and Hofseth LJ. A limited role of p53 on the ability of a Hexane fraction of American ginseng to suppress mouse colitis. J Biomed Biotechnol. 2012; 2012:785739.(doi):10.1155/2012/785739. Epub 782012 Jul 785730 .

45. Cui X, Witalison EE, Chumanevich AP, Chumanevich AA, Poudyal D, Subramanian V, Schetter AJ, Harris CC, Thompson PR and Hofseth LJ. The induction of microRNA-16 in colon cancer cells by protein arginine deiminase inhibition causes a p53-dependent cell cycle arrest. PloS one. 2013; 8:e53791.

46. Luo Y, Arita K, Bhatia M, Knuckley B, Lee YH, Stallcup MR, Sato M and Thompson PR. Inhibitors and inactivators of protein arginine deiminase 4: functional and structural characterization. Biochemistry. 2006; 45:11727-11736.

47. Chumanevich AA, Poudyal D, Cui X, Davis T, Wood PA, Smith CD and Hofseth LJ. Suppression of colitis-driven colon cancer in mice by a novel small molecule inhibitor of sphingosine kinase. Carcinogenesis. 2010; 31:1787-1793. 